Pure Appl. Chem., Vol. 73, No. 1, pp. 9-15, 2001.

(C) 2001 IUPAC

\title{
In situ speciation measurements. Using diffusive gradients in thin films (DGT) to determine inorganically and organically complexed metals*
}

\author{
Hao Zhang and William Davison ${ }^{\dagger}$ \\ Department of Environmental Sciences, Lancaster University, Lancaster, LA1 4YQ, \\ UK
}

\begin{abstract}
The possibilities of using diffusive gradients in thin films (DGT) and anodic stripping voltammetry (ASV) to perform speciation measurements in natural waters are discussed. Both techniques measure labile species, but different approaches have been used to discriminate organic $\left(C_{\text {org }}\right)$ and inorganic $\left(C_{\text {inorg }}\right)$ metal complexes. In DGT, metals are bound to a resin after passing through a hydrogel that serves as a well-defined diffusion layer. DGT devices with different hydrogels that impede the diffusion of humic substances by different amounts were deployed in solutions of copper and humic substances. Devices with a gel composition that greatly restricted the diffusion of humic substances, but only retarded the diffusion of $\mathrm{Cu}$ ions slightly, could be used directly to determine $C_{\text {inorg }}$. By using different, more open pored gels, which allowed some passage of humic substances, it was possible to determine both $C_{\text {org }}$ and $C_{\text {inorg }}$. The two separate measurements of $C_{\text {inorg }}$ obtained using the two DGT approaches agreed well. At the high concentrations of $\mathrm{Cu}$ used there was good agreement with the predicted distribution from the speciation code WHAM. At the lowest $\mathrm{Cu}$ concentration, the proportion of $C_{\text {inorg }}$ estimated using DGT was higher than with WHAM. Possibilities of errors in the DGT or modeling approaches are discussed.
\end{abstract}

\section{INTRODUCTION}

Quantification of all chemical species present in natural waters has long been a goal of environmental chemists. It underpins understanding of geochemistry and of the uptake of nutrients and toxicants by biota. Great strides have been made in the last two decades in appreciating trace metal complexation, particularly through the application of the techniques of anodic stripping voltammetry (ASV) [1] and competitive ligand exchange, including cathodic stripping voltammetry [2,3]. Yet, as understanding has advanced and the true complexity of the distribution of ligand binding strengths has been recognized, our ability to quantify fully the chemistry of natural waters has apparently receded [4].

Another feature of the chemistry of natural waters that is increasingly being recognized is the dynamics of the interactions [5]. Changes in chemical forms occur both continuously and episodically through many processes, including colloidal pumping [6], release from or uptake by biota [7], and gaseous exchange [8]. Collecting and storing samples may disrupt these processes and can introduce other perturbations, such as $\mathrm{pH}$ changes, that can alter the chemistry of the sample from its natural state. Buffle et al. [9] have argued strongly that, ultimately, fully reliable information on the distribution of chemical species in a natural water can only be achieved if measurements are made in situ so that the

*Lecture presented at the $11^{\text {th }}$ European Conference on Analytical Chemistry (EUROANALYSIS XI), Lisbon, Portugal, 3-9 September 2000. Other presentations are published in this issue, pp. 1-54.

$\dagger$ Corresponding author 
problems of sampling are bypassed. Competitive ligand exchange techniques cannot be used without perturbing the sample because the measurement involves adding a ligand (and often a buffering reagent) and reestablishing a new equilibrium situation. Colombo et al. [10] have accomplished this procedure on-line in pumped water samples on board ship to provide virtually continuous measurements. However, as reagents are still added and the samples degassed, composition is inevitably changed from the in situ condition in the 2-3 min that elapses from sample removal to measurement. While ion-selective electrodes are in principle an ideal tool for in situ measurement and have been used in certain special conditions as microelectrodes [11], they generally lack the required sensitivity for trace metals. Voltammetry, however, has the correct attributes for in situ measurement of metals, as it minimally perturbs the sample and in stripping mode is extremely sensitive. ASV has been used in situ to measure trace metals directly in water columns [12] and direct voltammetry to measure iron and manganese in the pore waters of sediments [13].

One of the difficulties encountered in using voltammetry directly is defining exactly what it measures. Generally, free metal ions are regarded as electroactive. However, all those chemical species that can dissociate rapidly, to yield the free metal ion as it is removed at the electrode, will also be measured [14]. This usually embraces all inorganic species and many organic complexes, including most metal complexes with humic and fulvic substances. Very strong complexes are not measured, as their kinetics of dissociation are too slow. This mixture of complexes that contribute to the signal leads to interpretation difficulties, as complexes of different sizes have different sensitivities and calibration curves due to their different diffusion coefficients. In their titrations of natural waters with metal ions while measuring the ASV response, Donat et al. [2] have elegantly solved this problem by carefully selecting the conditions to ensure that only labile inorganic species are measured. Complexed metals generally require more negative deposition potentials than simple metal ions. By choosing an optimum potential, metal can be accumulated from simple labile complexes while effectively excluding labile, organically complexed metal. The distinction is further enhanced by using a thin-film rotating disc electrode to ensure a very thin diffusion layer, which allows less time for metal-organic complexes to dissociate as they are transported to the electrode. This commendable procedure would be difficult to use in situ, however. Pei et al. [15] have chosen instead to use mercury-coated microelectrodes which have a thin spherical diffusion layer that is not influenced by solution flow. They have demonstrated that natural surfactants can bias in situ measurements and have overcome the problem by encasing the electrode in a layer of gel. Use of a gel has potential for further discriminating the measured species on the basis of size as well as lability.

An analogous technique for measuring labile metals has been created by backing a well-defined layer of gel with a binding agent, such as Chelex [16]. The technique is known as diffusive gradients in thin films (DGT), as it relies on establishing a linear diffusion gradient through the gel while it is deployed. The accumulated mass of metal, $M$, is measured after deployment by eluting the metal with acid, and eq. 1 used to calculate the concentration, $C$, in the deployed solution.

$$
C=M \Delta g /(D t A)
$$

$D g$ is the thickness of the diffusion layer, $D$ is the diffusion coefficient, $t$ is the deployment time and $A$ is the area of the exposed gel. As the device can be configured as a simple disc in a plastic holder, it is readily deployed in situ [17]. Like ASV, DGT measures both labile inorganic and organic species [18]. Quantitative determination of these two groups of species has been achieved for $\mathrm{Cu}$ by making parallel measurements using devices equipped with gels of different pore sizes [19]. The method relies on most labile metal-organic complexes being fairly large molecules, and small, labile metal-organic complexes being negligible compared to the total inorganic metal species. Here we report the measurement by DGT of both labile inorganic and labile organic $\mathrm{Cu}$ species in solutions containing humic substances extracted from peat. 


\section{EXPERIMENTAL PROCEDURES}

\section{DGT preparation and procedures}

Procedures for gel preparation have been given in detail previously [20]. The diffusional properties, with respect to simple metal ions, fulvic substances, and humic substances extracted from both water and peat, of the three gels used in this work have been reported previously [19,20]. The three gels are made of the following: (a) 1.5\% pure agarose (AGE), (b) an acrylamide monomer cross-linked with a patented agarose derivative (DGT Research) (APA), and (c) an acrylamide monomer cross-linked with bis-acrylamide (RG). Both the AGE and APA gels have open structures that allow free diffusion of simple metal ions, with diffusion coefficients equivalent to those in water. They retard the diffusion of humic substances slightly, with the effect being more pronounced for the APA gel. Restricted gel (RG) has a much smaller pore size. It retards the diffusion of humic substances much more markedly and slightly retards the diffusion of simple metal ions.

The Chelex resin was cast into a separate layer of the APA gel, known as the resin-gel. It comprised 2g of Chelex 100 ( $\mathrm{Na}$ form, 200-400 mesh) set in $10 \mathrm{~m} \ell$ of gel solution. All gels were hydrated in ultra-pure water, MilliQ (MQ), for at least $24 \mathrm{~h}$ before use, to allow them to establish a new stable dimension. Diffusive gels were soaked for a further $24 \mathrm{~h}$ in $0.1 \mathrm{M} \mathrm{NaNO}_{3}$ solution to eliminate diffusional artefacts present at low ionic strengths [20].

Gel holders based on a simple, tight-fitting, piston design with a 2-cm diameter window were used for all measurements [21]. They were assembled with wet components to prevent entrapping air bubbles. A 0.8 -mm-thick diffusive gel was placed on top of a $0.4-\mathrm{mm}$-thick resin gel, resting on the piston surface with the side packed with resin beads facing upwards. After adding a $135-\mu \mathrm{m}$-thick, $0.45-\mu \mathrm{m}$ pore size, cellulose nitrate membrane on top of the diffusive gel, the front cap was pressed down lightly to form a good seal. The membrane behaves as an extension of the diffusion layer [20].

\section{Analysis}

After deployment, the resin gel layers were carefully removed from the DGT assemblies and placed in 1.5-mL vials. One milliliter of $1 \mathrm{M} \mathrm{HNO}_{3}$ was added and left for a day. Electrothermal atomic absorption spectroscopy (ETAAS) was used to measure the concentration of $\mathrm{Cu}$ in the eluent, from which the accumulated mass could be calculated [19]. Total concentrations of metals were measured by ETAAS directly. ASV used an Ecochimie Autolab PSTAT 10, DAC 124 coupled to a Metrohm VA electrode stand. $\mathrm{Cu}$ was deposited at a mercury drop electrode at $-0.4 \mathrm{~V}(\mathrm{Ag} / \mathrm{AgCl})$ for $60 \mathrm{~s}$. After a 5-s rest period, differential pulse scans were performed from -0.35 to $0 \mathrm{~V}$.

\section{RESULTS AND DISCUSSION}

\section{Principles of measurement}

The theoretical background to the use of DGT with different gel compositions to measure inorganic and organic species separately has been elaborated [19]. For any DGT device, the mass of metal accumulated $\left(M_{\mathrm{DGT}}\right)$ is the sum of the contributions from both labile inorganic $\left(M_{\mathrm{inorg}}\right)$ and organic $\left(M_{\mathrm{org}}\right)$ species (eq. 2)

$$
M_{\mathrm{DGT}}=M_{\text {inorg }}+M_{\text {org }}
$$

According to DGT, theory based on Fick's laws of diffusion [18]

$$
\begin{aligned}
& M_{\text {inorg }}=\left(D_{\text {inorg }} C_{\text {inorg }} A t\right) / \Delta g \\
& M_{\text {org }}=\left(D_{\text {org }} C_{\text {org }} A t\right) / \Delta g
\end{aligned}
$$


$C_{\text {inorg }}$ and $C_{\text {org }}$ are the concentrations of labile inorganic species and labile organic species that can be measured by DGT. It is assumed that all simple inorganic species have the same effective diffusion coefficient in the gel, $D_{\text {inorg }}$, and that all metal organic complexes can be represented by a mean diffusion coefficient in the gel, $D_{\text {org. }}$. In fresh waters, humic substances dominate the organic ligands. Their diffusion coefficients have been shown to be similar irrespective of their original source [22]. Combining eqs. 2,3 , and 4 results in eq. 5 .

$$
M_{\mathrm{DGT}}=\left(D_{\text {inorg }} C_{\text {inorg }}+D_{\text {org }} C_{\text {org }}\right) A t / \Delta g
$$

If several devices with different gel compositions, but with the same surface area and diffusion layer thickness, are deployed for the same time, the term $A t / \Delta g$ is a constant, denoted by $K$. Equation 5 can then be rearranged to eq. 6 .

$$
M_{\mathrm{DGT}} / K D_{\text {inorg }}=C_{\text {inorg }}+\left(D_{\text {org }} / D_{\text {inorg }}\right) C_{\text {org }}
$$

Plots of $M_{\mathrm{DGT}} / K D_{\text {inorg }}$ versus $D_{\text {org }} / D_{\text {inorg }}$ have been shown to be linear for $\mathrm{Cu}$ at various concentrations in solutions of both fulvic and humic acids extracted from natural waters [19].

Three different types of DGT devices, with AGE, APA, and RG gels were deployed for from 2 to 8 $\mathrm{h}$, depending on the copper concentration, in solutions containing $0.1 \mathrm{M} \mathrm{NaNO}_{3}, 2 \mathrm{mM}$ tris and humic acid extracted from peat. This extract, supplied by J. Lead, had been previously well characterized, and the molecular weight of 16500 determined by ultra centrifugation [23]. The $4 \mathrm{~L}$ of well-stirred solution were maintained at a known temperature in the range $15-22{ }^{\circ} \mathrm{C}$. The diffusion coefficient of the humic substances at $20{ }^{\circ} \mathrm{C}$ in the AGE gel immersed in $0.1 \mathrm{M} \mathrm{NaNO}_{3}$ with tris buffer (pH 7.8) was $7.410^{-7} \mathrm{~cm}^{2} \mathrm{~s}^{-1}$ and in the APA gel was $3.510^{-7} \mathrm{~cm}^{2} \mathrm{~s}^{-1}$. Values were not available for the restricted gel, as they were too low to measure in the timescale of the experiment. Copper was added to create three solutions used in experiments A, B, and C, with total copper contents of 410, 1105, and $1910 \mathrm{nM}$. With only two data points for the APA and AGE gels, eq. 6 can be rearranged to calculate $C_{\text {inorg }}$ and $C_{\text {org }}$ directly (eqs. 7 and 8 ) rather than plotting a line.

$$
\begin{aligned}
& C_{\text {inorg }}=\left({ }^{\mathrm{AGE}} M /{ }^{\mathrm{AGE}} D_{\text {org }}-{ }^{\mathrm{APA}} M /{ }^{\mathrm{APA}} D_{\text {org }}\right) /\left[K\left({ }^{\mathrm{AGE}} D_{\text {inorg }} /{ }^{\mathrm{AGE}} D_{\text {org }}-{ }^{\mathrm{APA}} D_{\text {inorg }} /{ }^{\mathrm{APA}} D_{\text {org }}\right)\right] \\
& C_{\text {org }}=\left({ }^{\mathrm{AGE}} M /{ }^{\mathrm{AGE}} D_{\text {inorg }}-{ }^{\mathrm{APA}} M /{ }^{\mathrm{APA}} D_{\text {inorg }}\right) /\left[K\left({ }^{\mathrm{AGE}} D_{\text {org }} /{ }^{\mathrm{AGE}} D_{\text {inorg }}-{ }^{\mathrm{APA}} D_{\text {org }} /{ }^{\mathrm{APA}} D^{\mathrm{inorg}}\right)\right]
\end{aligned}
$$

${ }^{\mathrm{AGE}} M,{ }^{\mathrm{AGE}} D_{\text {inorg }}$, and ${ }^{\mathrm{AGE}} D_{\text {org }}$ represent mass of metal accumulated on the DGT device with the AGE gel and the diffusion coefficients of the inorganic and organic species in this gel. The APA and RG superscripts indicate the equivalent terms for the other gels. From previous measurements [20] it is known that ${ }^{\mathrm{AGE}} D_{\text {inorg }}=6.2010^{-6},{ }^{\mathrm{APA}} D_{\text {inorg }}=6.2810^{-6}$ and ${ }^{\mathrm{RG}} D_{\text {inorg }}=4.5010^{-6}\left(\right.$ all $\left.\mathrm{cm}^{2} \mathrm{~s}^{-1}\right)$.

\section{Measurement of $C_{\text {inorg }}$ and $C_{\text {org }}$}

The measured values of $C_{\text {inorg }}$ and $C_{\text {org }}$ are shown in Table 1 and Fig. 1, along with the total dissolved $\mathrm{Cu}$ measured by ETAAS, the ASV measured $\mathrm{Cu}, C_{\text {inorg }}$ measured by a single restricted gel, $C^{\mathrm{s}}{ }_{\text {inorg }}$ (see below), and the distribution of $\mathrm{Cu}$ species calculated using the speciation code WHAM [24) from the total concentrations of dissolved copper and humic substances. The sum of the inorganic and organic species measured by DGT agrees very well with the total concentration measured by AAS, confirming the accuracy of the DGT measurement. The ASV result lies between the concentration of inorganic species and the total dissolved concentration. As ASV was calibrated by standard addition of $\mathrm{Cu}^{2+}$ to the solution, the measurement effectively assumes that all species have this same high diffusion coefficient. In fact, the metal complexes of these relatively large peat-derived humic substances can be expected to have a diffusion coefficient in water approximately one fifth of that of the free metal ion [20]. The most conservative estimate is that they would diffuse more slowly than the free metal ion by a factor of 3 [22]. Therefore, the ASV signal would be expected to be equivalent to the DGT measurement of inorganic species plus $0.2-0.3$ times the organic species measurement. For the two higher cop- 
Table 1 Results from experiments, A, B, and C, at three different total $\mathrm{Cu}$ concentrations in solutions of $0.1 \mathrm{M} \mathrm{NaNO}_{3}, 2 \mathrm{mM}$ tris and $1 \mathrm{mg} / \mathrm{l}$ humic acid. The measured masses, $M$, accumulated by DGT assemblies with RG, APA, and AGE gels are shown. Concentrations of total $\mathrm{Cu}$-inorganic species for each solution are calculated from the two DGT-measured masses with APA and AGE gels $\left(C_{\text {inorg }}\right)$, from the DGT mass from the RG gel $\left(C_{\text {inorg }}^{\text {s }}\right)$ and using the WHAM speciation code $\left(W_{\text {inorg }}\right)$. Concentrations of total copper-organic complexes for each solution are calculated from the two APA and AGE gels $\left(C_{\text {org }}\right)$ and from the WHAM speciation code $\left(W_{\text {org }}\right)$.

\begin{tabular}{lccc}
\hline Experiment & A & B & C \\
\hline$[\mathrm{Cu}]_{\mathrm{T}}$ & $410 \pm 28$ & $1105 \pm 64$ & $1910 \pm 56$ \\
\hline$M_{\mathrm{RG}}$ (nmoles) & 483 & 1006 & 1476 \\
$M_{\mathrm{APA}}$ (nmoles) & 1069 & 1600 & 2305 \\
$M_{\text {AGE }}(\mathrm{nmoles})$ & 1598 & 1966 & 2659 \\
$C_{\text {inorg }}(\mathrm{nM})$ & 31 & 228 & 618 \\
$C_{\text {inorg }}^{\text {s }}(\mathrm{nM})$ & 34 & 232 & 638 \\
$W_{\text {inorg }}(\mathrm{nM})$ & 2.5 & 166 & 716 \\
$C_{\text {org }}(\mathrm{nM})$ & 372 & 817 & 1252 \\
$W_{\text {org }}(\mathrm{nM})$ & 408 & 939 & 1194 \\
\hline
\end{tabular}

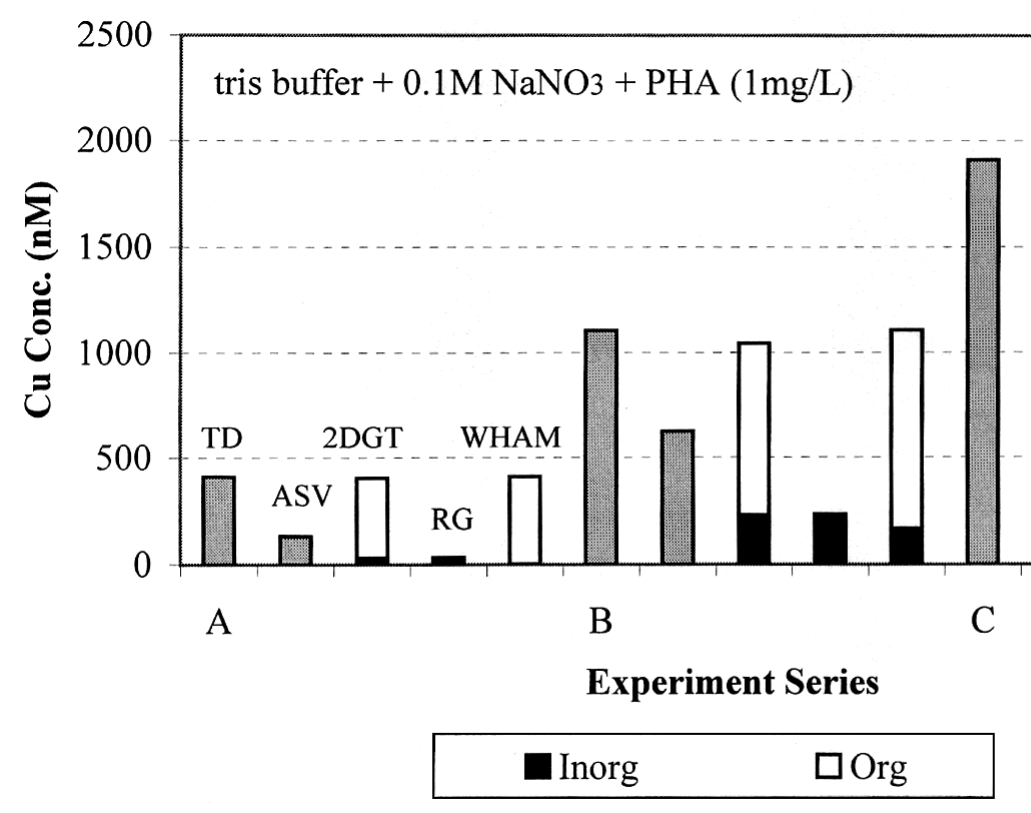

Fig. 1 Measurements, for each experiment A, B, and C, of total dissolved $\mathrm{Cu}$ (TD), labile Cu by ASV (ASV), inorganic and inorganic $\mathrm{Cu}$ by two DGT gels (2DGT), inorganic $\mathrm{Cu}$ by one restricted gel (RG), and the distribution of inorganic and organic $\mathrm{Cu}$ calculated using WHAM (WHAM).

per concentrations, the ASV signal is higher than this, as found previously [19]. There are several possibilities for this discrepancy, including: (a) a problem with the ASV measurement or calibration, (b) overestimation of the inorganic species by DGT, and (c) there being a greater proportion of Cu-humic complexes with molecular weights and diffusion coefficients less than those assumed. 
DGT can be used, like ASV, to calculate concentration from a single measurement assuming that only the diffusion coefficient for the free metal ion applies. However, for the most restricted gel, RG, the diffusion coefficient of peat humic substances is extremely low. Judging from the diffusion of aquatic humic substances in different gels and the relationship of the known diffusion coefficients of peat and aquatic humic substances, it is probably about 0.02 times the diffusion coefficient of inorganic copper species [20]. Therefore, this direct measurement by DGT would be expected to differ very little from the measurement of inorganic species using two different gels. This is exactly what is found in practice, with excellent agreement between $C_{\text {inorg }}^{\mathrm{s}}$ and $C_{\text {inorg }}$ (Table 1, Fig. 1). Arguably, $C_{\text {inorg }}^{\mathrm{s}}$ measured with a single restricted gel is more accurate than $C_{\text {inorg }}$ obtained using of two separate gels, as it is more direct and does not involve the subtraction of potentially quite similar terms (eq. 7), with consequent summation of errors.

For the two higher concentrations of $\mathrm{Cu}$, there was good agreement between the predicted distribution of species using the WHAM model and the measured values (Fig. 1). The effective binding constants used in the WHAM model were derived by fitting the model to numerous reported data sets from laboratory experiments on the binding of metals to humic substances [24]. Therefore, assuming that the mechanistic base of the model adequately describes the effects of changes in solution composition, such as ionic strength and $\mathrm{pH}$, the model effectively acts as a conduit for comparing the past data on coppermetal binding with the results and conditions of this work. Clearly, agreement between DGT and other measurements is good. This is not the case, however, for the lower concentration of total copper where WHAM (and therefore previous data) would suggest more complexation of copper with organic matter $(99.4 \%)$ than measured by DGT $(92.3 \%)$. There is a possibility that the DGT procedure may overestimate inorganic copper species when they represent a small proportion of the total dissolved copper. For the experiment with the AGE and APA gels, this could occur if a small fraction of the organic complexes has a sufficiently low molecular weight to diffuse appreciably more rapidly in the gels than expected from the measured mean diffusion coefficient. However, the good agreement with the measurement using only the restricted gel argues against this idea. Humic substances diffuse much less freely in this more restricted gel, and, therefore, any tailing of the diffusion coefficient to higher values would have affected the measurement with the RG gel much less than that with the AGE and APA gels. It may be that previous measurements used to parametize WHAM did not cover these low concentrations of $\mathrm{Cu}$ and humic substances or that those that did were inaccurate. Further detailed measurements, focusing on higher ratios of humic substances to copper ions than those used in this work are clearly required to examine further the performance of DGT compared to other techniques.

DGT should work particularly well as a speciation technique with peat-derived humic substances, as their relatively large molecular weight ensures a good distinction in diffusion coefficients from inorganic species. Use of the restricted gel in a single measurement then works well to give an accurate discrimination of inorganic and organic species. With lower-molecular-weight species, greater reliance has to be placed on parallel deployments with at least two gels. For the same concentration of $\mathrm{Cu}$ (e.g., 1.1 $\mathrm{mM}$ ), DGT has shown increasing complexation with higher-molecular-weight humic substances, as found previously [24].

\section{ACKNOWLEDGMENTS}

We thank Jamie Lead for supplying the humic substances and NERC for funding a Fellowship for Hao Zhang.

\section{REFERENCES}

1. K. H. Coale and K.W. Bruland. Limnol. Oceanogr. 33, 1084 (1988).

2. J. R. Donat, K. A. Lao, K. N. Bruland. Anal. Chim. Acta. 284, 547 (1994).

3. C. M. G. van den Berg. Mar. Chem. 15, 1 (1984). 
4. K. W. Bruland, E. L. Rue, J. R. Donat, S. A. Scrabal, J. W. Moffett. Anal. Chim. Acta. 405, 99 (2000).

5. A. T. Stone and J. J. Morgan. In Aquatic Chemical Kinetics, W. Stumm (Ed.), pp. 1-4, Wiley Interscience, New York (1990).

6. B. D. Honeyman and P. H. Santschi. Deep Sea Res. 47, 951 (1989).

7. M. F. C. Leal, M. T. S. D. Vasconcelos, C. M. G. van den Berg. Limnol. Oceanogr. 44, 1750 (1999).

8. P. S. Liss. In Air-Sea Exchange of Gases and Particles, P. S. Liss, W. G. N. Slinn (Eds.), p. 241, Reidel, Dordrecht (1983).

9. J. Buffle, M. L. Tercier, N. Parthasarathy, K. J. Wilkinson. Chimia. 51, 690 (1997).

10. C. Colombo, C. M. G. can den Berg, A. Daniel. Anal. Chim. Acta 346, 101 (1997).

11. B. Muller, K. Buis, R. Stierlie, B. Wehrli. Limnol. Oceanogr. 43, 1728 (1998).

12. M. L. Tercier, J. Buffle, A. Zirino, R. R. De Vitre. Anal Chim. Acta 237, 429 (1990).

13. P. J. Brendel and G. W. Luther. Environ. Sci. Technol. 29, 751 (1995).

14. W. Davison. J. Electroanal. Chem. 87, 395 (1978).

15. J. H. Pei, M. L. Tercier-Waeber, J. Buffle. Anal. Chem. 72, 161 (2000).

16. W. Davison and H. Zhang. Nature 367, 546 (1994).

17. S. Denny, J. Sherwood, J. Leyden. Sci. Tot. Environ. 239, 71 (1999).

18. H. Zhang and W. Davison. Anal. Chem. 67, 3391 (1995).

19. H. Zhang and W. Davison. Anal. Chem. 72, 4447 (2000).

20. H. Zhang and W. Davison. Anal. Chim. Acta 398, 329 (1999).

21. H. Zhang, W. Davison, R. Gadi, T. Kobayashi. Anal. Chem. Acta. 370, 29 (1998).

22. J. R. Lead, K. J. Wilkinson, K. Starchev, S. Canonica, J. Buffle. Environ. Sci. Technol. 34, 1365 (2000).

23. J. R. Lead, J. Hamilton-Taylor, N. Nesketh, M. N. James, A. E. Wilkinson, E. Tipping. Anal. Chim. Acta 294, 319 (1994).

24. E. Tipping. Computers and Geosciences 20, 973 (1994). 